Review Article

\title{
Practice and Theory in the Moral Development: Question of Awareness
}

\author{
Adrian Oscar Dongo Montoya \\ College of Phylosophy and Sciences, University of São Paulo State, Marília, SP, Brazil.
}

\section{Email address:}

dongomontoya@hotmail.com

\section{To cite this article:}

Adrian Oscar Dongo Montoya. Practice and Theory in the Moral Development: Question of Awareness. Education Journal. Vol. 9, No. 1, 2020, pp. 1-8. doi: 10.11648/j.edu.20200901.11

Received: October 21, 2019; Accepted: December 25, 2019; Published: January 6, 2020

\begin{abstract}
The study of moral development, as well as that of affective and intellectual life, highlights the need to establish which relations exist between the child's practical action and his reflection on it. However, analyzing these relationships requires considering the process that can make them intelligible, which is awareness. In this paper, we analyzed these relationships from some basic questions: How does the child think the moral rules while performing their acts and after they are closed? How do children judge their own acts and those of others? Is there correspondence between moral judgments and moral practice in the child? Is there a difference in the quality of thought and judgment between a child who is trained according to a heteronomous moral and another who is formed according to an autonomous moral? How does this occur and what are the difficulties in becoming aware of feelings of mutual affection, since this is the central core of the moral of autonomy and the moral of the good? In this study, these issues were analyzed, and appropriate solutions were pointed out according to Jean Piaget's psychogenetic theory, when an autonomous moral education is intended. It also showed the implications of pedagogical practices that make the child's awareness unfeasible.
\end{abstract}

Keywords: Awareness, Practice and Theory, Moral Development

\section{Introduction}

Although Piaget has written a little about moral life - only one book 1932 and some articles 1927, 1930, 1931, 1934, 1988a, 1988b, about the subject - it cannot be denied the great importance of moral in his work. Still, even though the elaboration of a moral theory is an unfinished project, the work left by him shows us a coherent theoretical basis about such topic. Authors [1-3] try to emphasize Piaget's intention when formulating a moral and knowledge theory; others, like [4-6] and [7], recognize this goal since Piaget's youth, shown in his autobiographic work Recherche [8].

According to [4] and [7], Piaget, in this work, aims at formulating a moral theory from certain fundamental biological and philosophical beliefs. Such beliefs are related to the systemic and dynamic conception of life's organization and knowledge. Systemic, in the sense of relation among the whole and the parts, in all levels and scopes of organization; dynamic, in the sense of understanding the difference and integration among real and ideal balances. The real balances are unstable and tend to be ideal and stable. So, the development of moral feelings, as well as, the knowledge, should be explained due to this movement.

In this perspective, the young Piaget [8] proposes treating the moral in its specific nature. Consequently, in order to go further this theory, the author will search for its roots in feelings opposed to utilitarianism and to amorality, it means, in the altruism [8].

The origins for altruism must be looked for in the first behaviors and feelings of the child and observe its evolution until the moral fundaments are constituted. The big issue is that between this behavior and feelings, and the moral, there is an adult authority intervention, which produces a "short-circuit" in the evolutionary course; besides that, the problem is overcoming the internal difficulties of his/her evolution. Such evolution consists of overcoming the initial structural nature to build up another one qualitatively different.

Therefore, aiming at understanding Piaget's theoretical 
system about moral development, we will focus on the analysis of his main psychological work in order to observe the thesis of functional continuity and the structural transformation of primitive actions and feelings from the child. In other words, to observe, how the altruist primitive actions and feelings become conscious and structurally different. In this process of transformation, we will highlight the role of psychological mechanism in the process of awareness.

Piaget's theory about moral development has not always been understood and accepted by its critics and followers. There are still divergences in relation to action and awareness, behavior and representation. In the research made by [9], which focus on the relation of judgment and moral action in the theories of morality, it is seen differences and also oppositions by its followers.

So, for Lawrence Kohlberg, who stands out as one of the followers, the action does not precede the judgement as well as the awareness does not have a central role in the highest levels of morality [10]. On the same way, for many of its critics, the relation that exists between action and awareness is still too controversial.

Although there is such controversy, it is believed that the intelligibility of such relation becomes meaningful when it is inserted into a theoretical system.

In order to achieve our aim, we base our work on Piaget's "The moral judgment in the child" [11] and other complementary articles about the topic. [12-17]

Besides that, we will base it on Piaget's modern researches about processes and mechanisms responsible for psychological development, such as "Awareness" [18], "To do and to understand" [19] and "Reflexive abstraction" [20]. Articles and work from other authors have also contributed for our conjecture [21-23].

The issue "awareness", in Piaget's theory, is a topic of great importance, which deserves further studies in different areas of human behavior, although it was given little attention in the psychological research, as Piaget, himself, highlights in his study about such subject $[19,20]$. For him, the awareness is a huge area to be researched, but still not so well known, even thought is quite important for Psychology and Epistemology. In other words, the psychologists were interested, specially, in knowing when the awareness really happens or not, but they have neglected the other part, which is complementary and consists of stablishing "how" it processes itself.

Piaget's theory about "awareness" involves the relation between practice and theory and goes beyond studies concerning the moral life. Due to this, in the study about "The moral judgement in the child" [11], it is placed an issue which can be formulated in the following terms: the verbal or theoretical thought - the thought that acts on evoked representations, making use of language and not on things the person acts and notice daily - consists of spontaneous thought awareness, with all systematic deformations, which occur, linked to practice or verbal thought cannot maintain any relation with the last one?

According to Piaget [19], such problem is important for human psychology, since the human being is considered the one who makes speeches. In the speech, the words express the actions, or they have no relation with it? The study of the child conducts to the same general question: what is the verbal thought of the child towards his active and concrete thought?

The child's study gets relevant importance because the theory may be essential for psychological and social human life. With effect on philosophical area, Piaget [11] highlights two important opposite conceptions: the ones who defend a relation between moral and practice (either the first one serves as origin to it, or the reflection is the awareness of such action) and the ones who defend the opposite. It means, there could be logical actions or not logical (instinctive or affective ones) independently of speeches. For this second conception, a vague vocabulary would be added to these actions: it would be the moral theories that would not have relation to the practice.

What about the studies concerning children towards this fundamental theoretical question? Do the children verbal judgements, related to lack of moral made by hypothetical subjects, reported through the history, have relation to its actions or constitute a vocabulary with no relation to effective actions? In other words, does the judgement made by children, concerning moral transgressions, correspond or not to judgements made when practicing these rules? The results of survey, about rules of the game, made by Piaget [11] lead to a correspondence between theoretical judgements and moral practice. The issue is: Which is the source of such relation and the way the subject becomes aware of relations made in moral practice?

Therefore, the question Piaget elicits is not only knowing how the child practices his moral practice, but also, how the child judges the well or the bad in his own practice of acts and out of them. It means, checking if the judgements of values shown through questionnaires about acts from other hypothetical children correspond or not to evaluations occurred during their own practice.

In the intellectual field, Piaget [24-25] shows that the verbal thought is late in relation to scheme or "operations" built in the action plan, which will be rebuild in the representation plan. In this process, old difficulties, already overcome in the practice plan, appear again in the verbal pan. That's why there are discrepancies between the verbal construction phase and the practice phases. In the moral field, it is possible that there may be detour and delay between theoretical value judgement and the concrete evaluations of a child. What if, the first one consists of being aware properly, in relation to the second ones?

There are children who in the verbal or theoretical plan take into consideration the intentions in order to evaluate the acts from other people (objective responsibility), but when it comes the question about personal subjects, take into consideration the intentions relevant for the moment. It is possible, in such case, that the theoretical moral judgement, is simply late in relation to practical moral judgement and that corresponds to a current outdated phase. However, it is also possible that no connection may exist. In this case, the moral theory of the child will be just a simple vocabulary, with no relation with his concrete evaluations. So, in this last case, 
wouldn't the thought of the child, up to 10 or 12 years, essentially, a repetition or a deformation of adult's thought, without moral evaluations from the child, in his practice?

The researches by Piaget concerning the game of rules, specific ally the ball game, reveal that between the action and theory there is a defined correspondence, it is not simple though. The egocentric practice, which goes along with a feeling of unilateral respect by the oldest one and by the adult, corresponds to a theoretical judgement that makes the rule a mystic and transcendental reality. The rational practice of the rule, which goes along its mutual respect, corresponds to a theoretical judgement which attributes to the rule characteristic of a whole autonomy.

Conti's research [23] verifies Piaget's hypothesis about the relations between practice and moral awareness during the game of rules, played with children from Brazil, using the game called "dodgeball". It shows that the elementary way to understand the rule when reflecting, is not a simple vocabulary, but, it is what the child thinks and feels in the initial activities (unilateral respect); it also shows that the knowledge of the rules in practice, is more developed than verbal thought and theoretical reflection; it proves that the delays for theoretical reflection about the rules obey the deformations inherent in mechanisms for reflection and to the fact of finding difficulties already overcome in practice (take into consideration the intentions of the opponents). This research evidences, finally, that although at the beginning there is a little of mismatch between practice and theory, at the end of the process such relation gets balanced as the cooperation among people improve. The more the structural obstacles are overcome egocentrism and constraint action - over the cooperation; the need of reciprocity becomes more evident in the awareness plan.

Referring to moral domain, Piaget spots the following hypothesis: the verbal judgement or theoretical judgment corresponds to concrete and practical judgements during the actions, and the years that precede the questionnaires. So, the theoretical verbal thought, even being late in relation to practical thought, it is related, somehow, to outdated phases of such practical thought (primary and elementary forms).

But, if the theoretical verbal thought which reflects the judgement of objective responsibility and the moral of duty, extends practical actions of unilateral respect, can extend what kind of practical actions? It is about a simple vocabulary or psittacism added to moral duty?

Piaget elicits this question taking into consideration the decisive contribution by Claparède about awareness. [26] For Piaget, being aware or developing awareness of true moral basis, which leads to autonomy, is limited by egocentrism and social constraint. This process is not restricted to children only; in adults, has a great importance in the mechanism for social life.

It is important to highlight that the theory and practice when talking about moral, is different if compared to theory and practice in intellectual areas. Although both shows sympathetic and analogue processes, one does not reduce to another, since actions and relations are different: intellectual area aims logical norms got from general coordination of actions done over objects (experimental contents); moral area aims moral norms linked to actions and coordination which demand a mutual affection. Because of that, the constructive process of the second one is harder than the first one. The moral rules transmitted by adults generate a phenomenalism and egocentrism, hard to be overcome, since for the world the child must obey, mystically, the adult, and understand it demands to structure the reality according to bigger and bigger complexity and deepness levels.

\section{Relation Between Practice and Theory When Forming Moral Duty}

Piaget's research about ways of moral constraint and realism shows that the first ways of moral reflections by children, concerning steal and lie have a basic feature: their actions are judged from material consequences and moral rules transmitted (by the book). The child does not take into consideration the characteristics and intentions of characters who infringe or make the moral failures. This way of judging defines itself as objective responsibility, which is caused by adult's constraint and infant egocentrism (the one which generates the unilateral respect).

The results of this survey show processes, which characterize great phases of the moral development: the child's theoretical thought obeys, in a first moment, to unilateral respect but after, to principles from mutual respect rule's internalization and subjective responsibility (autonomy moral).

We are not going deeper in the characterization of phases, neither explanations about individual and social factors, which interfere when forming moral realism and objective responsibility. But we intend to understand the relation of child's judgements and concrete actions. Are the verbal judgements only some vocabulary that overlaps the actions, with no link, or is it a thought that corresponds, correctly or not, to actions and thoughts? Is the objective responsibility, shown in theoretical judgements, a vocabulary or represents the thoughts made in practical life of kids?

The issue is the following: To what refer these theoretical verbal results in relation to effective moral thought of the child? Do the moral reflections, made spontaneously by the child or faced in stories presented by the researcher, constitute or not the prolongation of any effective thought?

For Piaget, the results of the survey about moral values as well as steal lie and disfiguration, show that theoretical reflection, in a child, begins by manifestation of objective responsibility and corresponds to moral real facts lived previously. The results also reveal that the theoretical moral reflection, when expressing the objective responsibility, consists of manifesting a state - quite prolonged - which resists its overcoming. As the relations of thought and actions are far of being so simple, the author insists on the need of understanding the true perspectives where situating such results. It means, the author situates it in developing 
"awareness" in moral norms. First of all, the moral realism, although it was a secondary formation in relation to a simple aspiration of well in children, constitutes the first notion of moral thought with awareness during their trials of reflection and formulation. It would agree with [24] about the process of awareness: what is the first one in action order is the last place in being aware.

Therefore, if the moral realism appears as a primitive phenomenon over verbal plan, it is not proved that it also happens in the practice plan, since in this plan; the need of mutual affection is already present in their moral life. In Piaget's conception, being aware of well, which is ulterior to duty awareness, constitutes the first condition of a true moral life: the need of mutual affection. In second place, the awareness constitutes a rebuilding process where the constructions already made in the practice action plan happen. That is why it would be in delay in relation to the activity itself.

Consequently, if moral realism in reflection plan corresponds to proper reality concerning moral action, such reality will not be found in the reflection level. But it will be found earlier, in the practice plan. So, the objective responsibility may be outdated in action plan, but subsist in the theoretical thought.

Trying to prove this assumption, the author shows, during the first years of child's moral development, facts of moral realism and objective responsibility, which correspond to phenomenon observed in the verbal plan.

The author shows three examples related to tidiness learning situations, food prescriptions and disfiguration, which are shown quite vivid and effective in 2-3-year-old children when evaluating, objectively, the responsibility. It is surprising the fact that, even being in environments that cultivates the autonomy of infant awareness, the received orders conduct to an evident moral realism. The rule that comes from parents provokes an awareness of duty, against all the ulterior remission parents do.

J., 01 year, eleven months and 28 days, is sick and has got laxative, and was warned about collateral effects. Although her mother's precautions concerning embarrassed situations, J gets really impressed when the medicine starts working out. She has felt sad (tears in the eyes, open mouth) and has shown the same feelings as the fact had happened in normal circumstances due to her negligence. [10]

J., 2 years old, 10 months and 7 days, is not well, and his mother has the feeling that the usual bowl of vegetables the child is used to eat is too much for hm. The child, after some portions of the food, shows a visible stuffiness but struggles to finish the bowl, because this is the rule. Adults try to distract him, but he keeps on his thought, even feeling no hungry anymore. When he tries to swallow the food, he can't. but when they try to take the bowl away, he complains again, as he was guilty for not finish it. They take it away; calm the kid down (reassuring it is not his fault, that some days we are hungrier than others, etc.) Although mother's care, the child starts crying. Even being comforted, the child is still hurt, but promises sleep well, etc. [10]
J., 2 and half years old, plays with a shelf. As it is quite fragile, it breaks immediately. J gets really upset, and it is very hard to convince her it was not her fault. [10]

These examples show that during the first years, the coercion from adult, even being tenuous, provokes a real moralism, quite stressed.

So, for Piaget, the moral realism which is observed later in the verbal plan, would be the indirect continuity of such primitive phenomenon.

However, between the spontaneous moral realism of first years and the theoretical moral realism, there is an intermediate one that is essential to consider: the judgement the child makes concerning people's behavior and not concerning his behavior anymore.

Concerning the child himself, one can differentiate, around 3 or 4 years old, the intentional faults and the involuntary ones. And consequently, the child is able to apologize, saying" it was not on purpose". And concerning kids who are close to him, the things happen in a very different way. In general, the kid is much more severe with others than with himself, presenting a severe judgement regarding faults from other kids.

The reason for that is since such behavior appears in a material way, earlier than being understood in its intention (subjective responsibility). That is why the child is led to confront, immediately, the materiality with the established rule and judging the acts according to this criterion, essentially objective. Only with a huge effort full of generosity and friendliness the child is able to resist to such tendency, like us adults, and try to understand the reactions from others regarding their intentions.

When evaluating people's behavior (intermediate cases), we get closer to an artificial situation, where the child considers acts, not directly observed, but described through a story, what could be the research by Piaget about moral judgment in the child.

If the moral realism takes longer regarding judgements of others, and less when it is individual, it's obvious such judgment will take even longer when referring to verbal examples presented in the previous stories.

So, for Piaget [10], getting awareness implied by all the theoretical reflection, not just repeat with some delay, but there is also delays and distortions inherent to own refection mechanism.

In fact, since the direct action succeeds or overlaps a real thought and it is released by the word or imagination, the spirit leads itself to dominate by a group of perspective illusions and, by egocentrism unconscious perspective (when the center is in the own view/opinion). According to other studies shown by the author [24, 25], in the intellectual domain, the child who thinks in the verbal plan faces several difficulties that have already been overcome, long time ago, by practical intelligence. In the same way, in the moral domain, the child will be conducted to series of judgments, with no mercy and no psychological understanding, showing a moral realism when agreeing to the ones who are considered guilty. [10].

Based on that, the spontaneous moral realism from first 
years, even becoming tenuous in the own behavior, an develop firstly, when evaluating people's behavior and in theoretical cases evoked by narrative and stories that were told.

In conclusion, the moral realism expressed in judgments about behavior from other people actually corresponds to something effective and spontaneous in the child's thought. Such realism can be overcome in practice area, but not in reflection area. The question is: Why does the moral realism take long, and it is so hard to overcome in the verbal reflection?

As it was mentioned before, every rule, either imposed by the oldest to the youngest, or by the adult to the child, starts being explicit to awareness before being accepted as something necessary for social relations, which exclude the submission to authority. During this phase, the strict moral realism may ally to practice seemed more moderate and egocentric.

Effectively, the spontaneous egocentrism of the child and the adult's coercion combine in their oppositions until the paradoxical commitments exist. This is the case of a child who seems quite severe towards others' lies, but they also lie when it is necessary.

The coercion reinforces the features of egocentrism as well as objective responsibility. Only the cooperation may free the children from egocentrism and coercion results and make it possible to develop the feelings of mutual affection and trust. Only the cooperation may make it possible to develop the feelings of generosity and consideration for others.

\section{Relation Between Practice and Theory During Moral Formation}

If the moral realism, in the first trials, takes longer the moral realism of initial practice, the moral of good, which bases the moral autonomy, takes longer an initial practice that is imposed into child's moral life? Does the good moral, which appears in the theoretical reflection, result in a process for becoming aware in practice?

The duty moral, concerning its original form, is essentially heteronomous, because the good means obey to the adult and the bad means acting on their own. Such bad behavior is more attractive because it is not coercive. The relations of children with their social environment are not only restricted to coercion and unilateral respect; there is need of mutual affection in their spontaneous actions and generosity attitude as well as sacrifices that are not socially prescribed and codified. There are several moments during child's affective life where they show feelings of protection and revenge towards kids who suffer from other kids.

For Piaget, this is the start for good moral, which will develop itself and will be present in some individuals as they make use of friendliness and mutual respect. As such actions only happen in relations of cooperation, one can say that good moral is a result of cooperation, different from duty moral, which is result of coercion and can lead only to heteronomy.

How do the children get to good moral and autonomy?
When talking about stealing and lying, it is observed a signal when children find that veracity and honesty are necessary in relations of mutual friendliness and trust. So, there is autonomy when awareness considers as necessary keep the truth, no matter the exterior pressure. The autonomy appears as reciprocity when the mutual respect is strong enough to show them the necessity of treatment others the same way they would like to be treated. Therefore, the moral autonomy demands another way of social relation, the cooperation, which promotes reciprocity in respect and consideration.

But the problem is finding the origin of need for mutual respect and reciprocity. Does this need impose itself over unilateral respect, result of social and cultural transmission, or is it a result of primitive awareness?

It is necessary to say that, for Piaget [10], neither the logical norms nor moral norms are innate in individual awareness. While the notion of sensorial motor intelligence is built in the first 18 months, the behaviors related to people (affective ones) are built in the beginning, from affective reactions, in which it is possible to find the basis for all subsequent moral conducts.

However, such affective relations cannot be qualified as moral. It is necessary to warn that, neither an act of intelligence can be qualified as logical, nor a trait of sensitivity can be considered moral. It will be considered moral when some norms mean structure and balance rules (inserted in internal rules of coherent reciprocity, which reflect perspectives of two or more people, as it will be observed in "mutuality of reciprocal actions"). Nothing allows affirming the existence of such norms during behaviors happening before language, since in this phase there are no changes of points of views between people.

The moral of good, in its ending, constitutes "a priori" when an obligatory and necessary character happens gradually in its own evolution and progressive balance. It is at the end, and not at the beginning of the process that the spirit is aware of immanent laws. But, which laws are immanent in the moral area?

If there is an addressed evolution and it aims at a balance, it must have something which is influencing from the beginning. But, in which way does it influence such evolution? Does it influence with a structure that organizes the content of awareness or with a functional balance law, where the spirit is not immediately aware and will only manifest itself through multiple structures happening successively? This "priori" is not a principle or structure, but a group of functional relations, which imply successive imbalance and balance (moments of conflicts and coherence between interlocutors). These functional relations constitute the reciprocity relations, which the spirit becomes aware at its end.

But, how do the spirit or the thought will take the norms from this functional balance? For Piaget, this happens during the formation of successive structures through being aware, also, progressive and appropriate: "It only takes, the spirit is aware of this functional search of organization and its laws, and translate, in structure what was only simple functioning (sensorial motor and affective activity), for allowing the emergence of specific rules of organization". [10] 
How does the awareness regarding reciprocity happen in the moral field?

The moral of good, as a way of superior balance in person's awareness, shows a natural difference towards moral and duty: where the second one takes to recognition of heteronomous laws, and the first one, with mutual respect, which there is no other law but mutuality, takes to constitution of interior norms of its own functioning (reciprocity law).

The child starts to practice, the mutual respect with no reason, which is not as easy as believed. After, once they are used to such balance of actions, it occurs a repercussion of form over content (reflection upon their own actions or upon mutual respect actions). The reciprocity is no longer considered fair, but essentially, the behaviors susceptible of indefinite reciprocity (universal and necessary). When it comes for justice, it is said: "Don't do to others what you don't want for you" leads to brutal equality. The child puts the forgiveness above revenge, not for weakness, but for believing revenge is endless (10-year-old boy). [10]

Piaget expresses this mutuality in simpler ways:

If $A$ respects $B$ and vice versa, it is because A was respected first by B, after A puts himself in B's shoes. This is a completely new operation in relation to simple respect: if $\mathrm{B}$ limits himself to respect A forever, B will recognize as values, all commands from A, even the arbitrary ones. On the opposite, if A identifies himself (morally) with B and submits his points of view to the reciprocity laws, the results from such mutual respect would be new, because the norms now recognized maintain interior to the same reciprocity.

Therefore, the feeling of good will result in inducing people to respect and situate themselves, mentally and emotionally, from others' perspectives. The constituent factor for moral of good is the reciprocity law of mutual feelings or affection between them.

However, how can we explain the delay of awareness for moral in relation to duty?

It is essential to remember that as moral of duty, the objective responsibility may be outdated in the action plan and still exist in the thought plan; in the moral of good, the mutual affection may be late in the awareness and reflection plan, but not in the action plan. Besides that, the younger kids are more tolerant when justifying their own failures and do it taking into consideration the intentions (not doing on purpose); and when evaluating close ones' faults, they become less rigorous than evaluating hypothetical ones. Therefore, kids, progressively, may become more tolerant and sympathetic with their close friends, may accept their difficulties and put themselves in other's shoes for mutual affection, even before understanding the same actions with hypothetical people.

This way, the overcoming of objective responsibility occurs in the development of mutual affection. However, why the delay for this last one? It is because of adult's presence and the initial attitude from the kid to submit himself to adult's authority.

The contradiction between first demanding for mutual affection and unilateral respect occur due to this paradoxical situation. The second one usually wins the first one. Only when the exercise of mutuality becomes strong the need of mutual respect, the imperative of moral of duty will win.

\section{Conditions for Moral Awareness and Its Pedagogical Implications}

This study shows that the speech and moral reflection are related to first practical attitudes of a child: the theoretical moral realism is related to first practices of a child, to primitive moral realism, which result from spontaneous attitude and rules transmitted by adults; the autonomous moral norm is also related to practical attitude, not because de obligation imposed by adult, but because the need of mutual affection. This means that the acceptation of the norms as a moral of good does not depend on the transmission only, but also, the awareness of reciprocity rules involved in feeling of mutual affection.

Being aware is not a simple translation, in representation plan of initial practice, but the extension of progressive reconstruction. The coordination made in practice (mutual affection, mutual respect, altruist actions, etc.) are organized and reorganized in the plan of representation and awareness when they are justified and defended. Concerning the results (solutions), given to conflicts, the reasons are taken into consideration. In this process, practice and reflection, it will be possible to reach, progressively, the necessary and universal ways of reciprocity. However, being aware in practice shows difficult problems to overcome. Egocentrism and adult coercion lead to a passive acceptation of rules imposed by adults, even before promoting the appropriate awareness of actions. Therefore, there is a mystic and rigorous respect of the rule, but, at the same time, an egocentric practice. The possibility of awareness for rules depends on the strength for mutual relations and not on a blind obedience or social traditions. It means, it depends on solidarity and cooperation relations.

If the previous analysis is true, there is no other way to promote the evolution for awareness but cooperation and reciprocity relations. And the first primordial requirement for moral evolutions is the social life of the child. However, the social life has not to do only with accepting passively the social rules but has to do with interaction and exchange for both parts. The cooperation can be seen as a propulsion tool for developing the moral life and knowledge. [27]

If the intellectual cooperation demands discussion, the moral cooperation demands much more: it requires mutual comparison for personal intentions and for the rules each one adopts; it conducts the child to judge, objectively, acts and commands from others, including adults; it requires putting yourself in other people's shoes when it refers to feelings and thoughts. Only in these experiences, the functional laws of moral actions (reciprocity and affection) could highlight themselves. Therefore, the intellectual development does not lead, necessarily, to moral development.

All in all, the awareness, which leads to autonomous moral, demands the following basic conditions:

First of all, the child is not able to be aware of behavior 
norms by themselves and constitute them. The social life is necessary to allow the child to be aware of spirit functioning and to transform the simple functional balance present in all mental activities into norms.

In second place, the relations of unilateral respect and coercion, between adults and children, contribute for the first logical and moral control. The problem is that such first type of control could not be enough to eliminate child's egocentrism and build up the real morality: "For considering a conduct as moral, is necessary more than just an agreement with external rules. It is necessary that awareness is linked to morality as an autonomous tool and is capable to appreciate the value of rules that are proposed". [10]

In third place, cooperation is the essential way of social trade, which promotes awareness of reciprocity rules. However, it is necessary to distinguish the cooperation in intellectual and moral areas.

In intellectual life, cooperation is reason for critics and awareness of logical norms present in collective and individual activities (coordination of social and individual actions). In intellectual area, the mutual control repels the spontaneous belief of egocentrism and blind trust in adult's authority. The discussion leads to objective reflection and verification. So, cooperation allows the recognition of principles of logic while normative laws necessary to the research, allow awareness of logical relations of reciprocity and perspective laws.

\section{Acknowledgements}

In what refers to moral realities, cooperation is source of critics and egocentrism overcoming. The cooperation is responsible for making the child judging, objectively, acts and commands from other people, including adults. This is made through mutual comparison of personal intentions and the rules each person adopts.

The cooperation repels, at the same time, egocentrism and moral realism (external rule for awareness). As a result, the rule is not external anymore and it is admitted as an independent tool, independent of authority. The moral rule of not lying becomes a link guaranteeing mutual trust. The awareness of good results of accepting norms of reciprocity - necessity of treating others the same way you would like to be treated. They are the ones that have become strong enough in order to overcome egocentrism as well as moral realism.

On the other hand, we agree with Piaget when he refers to the findings of psychological and sociological researches. According to him, although these findings are quite important for pedagogical theory and practice, they do not go further in good practices. It is necessary to test and developed hem into pedagogical practices. However, in our opinion, it is considered impossible not taking into consideration such findings since students are considered active and worthy of respect. The experiences, which aim democratic actions and republic principles, cannot consider "team work and self-government", which, not only promote child's socialization, but also the development of mutual reciprocity.

Developing awareness in the moral development is important for the educational and pedagogical work. The process from practical coordination to conceptual ones, demands certain necessary conditions: face to inter individual relationship conflicts is necessary that children reconstitute their own actions, through oral speech, towards others and vice versa. They must try to understand the reasons for such actions and must be willing to hear others' point of view. In an educative or pedagogical project, where it is wanted to promote moral autonomy - people acting for good - the dialogue must come from results of moral practice in order to analyze the reasons that have taken to the conflict or mutual agreement. It may happen between two people or a bigger group (classroom, any scholar institution). Therefore, the moral education projects aimed at reaching autonomy, must stop working with verbalism and centered in the adult authority (parents and teachers), and on the opposite, must be built in group environments, where conflicts might be discussed freely, like a real democracy.

The simple practice of a rule does not produce the development of autonomous moral, as well as the speech of moral good does not produce an authentic moral feeling.

\section{References}

[1] B. Freitag. Itinerários de antigona; a questão da moralidade. Campinas: Papiros, 1992.

[2] B. Freitag. Razão teórica e razão prática: Kant e Piaget. ANDE: Revista da Associação Nacional de Educação. São Paulo: Cortez, vol. 9, n. 15, pp. 55-68, 1990.

[3] B. Freitag. Piaget e a Filosofia. São Paulo: UNESP, 1991.

[4] J. J. Ducret. Jean Piaget: savant et philosophe; les années de formation, 1907- 1924; étude sur la formation des connaissances et du sujet de la connaissance. Genève: Droz, 1984, vol. I and II.

[5] J. Vonèche. La Première théorie de l'equilibre de Jean Piaget (1981). In: D. Maurice, J. Montenegro. Équilibre et équilibration dans l'oeuvre de Jean Pìget et au regard de courants actuals. Genève: Fondation Archives Jean Piaget, 1992, pp. 11-29.

[6] F. Vidal. Piaget before Piaget. Massachusset/ London: Harvard University Press, 1994.

[7] L. Freitas. A Moral na obra de Jean Piaget: um projeto inacabado. São Paulo: Cortez, 2003.

[8] J. Piaget. Recherche. Lausanne: La Concorde, 1918.

[9] L. de Souza; M. S. Vasconcelos. Juízo e ação moral: desafios teóricos em Psicologia. Psicologia e Sociedade, vol. 21, n. 03, p. 343-352, 2009.

[10] L. Kohlberg. The Psychology of Moral Development: The Nature and Validity of Moral Stages (Essays on Moral Development, vol. 2). New York: Harper \& Row, 1984.

[11] J. Piaget. (1932). O juízo moral na criança. (Transl. E. Lenardon.) São Paulo: Summus, 1994. 
[12] J. Piaget. "Le respecte de la règle dans les sociétés d'enfants". In: Le Nouvel Essor. Genéve, anne 22, n. 23, 1927.

[13] J. Piaget. "Le développement de l'esprit de solidarité chez l'enfant et la notion de justice chez l'enfant." In: Comment faire connaître la Societé des Nations et développer l'esprit de cooperation international: troisième cours pour le personnel enseigment. Bureau International d'Éducation. Genéve: BIE, 1930, pp. 52-7, 1930.

[14] J. Piaget. "L'esprit de solidarité chez l'enfant et la collaboration international". In: Recuil Pedagogique, vol. 2, n. 1, pp. 11-27, 1931.

[15] J. Piaget. Une éducation pour la paix est-elle possible? Bulletin de L'Enseignement de la Societé des Nations. Paris, n. 1, pp. 17-23, 1934.

[16] J. Piaget. "A educação da Liberdade". In S. Parrat and A. Tryphon. Jean Piaget: sobre Pedagogia. São Paulo: Casa do Psicólogo, 1998a.

[17] J. Piaget. "A educação da Liberdade”. In: S. Parrat, A. Tryphon. O desenvolvimento moral do adolescente em dois tipos de sociedade: sociedade primitiva e sociedade "moderna". São Paulo: Casa do Psicólogo, 1998b.

[18] J. Piaget (1974). A tomada de consciência. (Transl. E. B. Souza) São Paulo: Melhoramentos/ USP, 1977.
[19] J. Piaget. (1974). Fazer e compreender. (Transl. C. L. de Paula). São Paulo: Melhoramentos/USP, 1974.

[20] J. Piaget (1977). Abstração reflexionante. (Transl. F. Becker and P. B. Gonçalves da Silva.) Porto Alegre: Artes Médicas, 1995.

[21] Y. de La Taille. A importância da generosidade no início da gênese da moralidade na criança. Psicologia: Reflexão e Crítica, vol. 19, n. 1, pp. 9-17, 2006.

[22] M. Bronzato, R. Camargo. "Moral e afetividade em Piaget: os movimentos íntimos da consciência". In: $\mathrm{O}$ juízo Moral na Criança. Shème. São Paulo, vol. 3, n. 05, pp. 80-109, 2010.

[23] L. F. Conti. Prática e consciência da regra no jogo de "Bola queimada": contribuição para a educação física. Marília, SP: UNESP, 2015.

[24] J. Piaget (1945). A formação do símbolo na criança. Rio de janeiro: Guanabara/Koogan, 1973.

[25] J. Piaget (1936). O nascimento da Inteligência na criança. Transl. A. Cabral. Rio de Janeiro: Guanabara, 1987.

[26] E. Claparède (1929). A Escola sob Medida. 3.ed. Rio de Janeiro: Fundo de Cultura, 1973.

[27] J. Piaget (1965). Estudos sociológicos. (Transl. R. Di Piero) Rio de Janeiro: Forense, 1975. 